\title{
A retrospective study of ocular occurrence in domestic animals: 799 cases
}

\author{
P. Tamilmahan, M. M. S. Zama, Rekha Pathak, N. S. Muneeswaran and K. Karthik \\ Indian Veterinary Research Institute, \\ I zatnagar, Uttar Pradesh- 243 122, India \\ Corresponding author: P. Tamilmahan, email:drtamilmahan.bison@gmail.com \\ Received: 08-09-2012, Accepted: 25-09-2012, Published online: 16-02-2013
}

\section{How to cite this article:}

Tamilmahan P, Zama MMS, Pathak R, Muneeswaran NS and Karthik K (2013) A retrospective study of ocular occurrence in domestic animals: 799 cases, Vet. World 6(5):274-276, doi: 10.5455/vetworld.2013.274-276

\begin{abstract}
Aim: The present study was conducted to determine the approximate prevalence, distribution and different types of ocular disorders in domestic animals.

Material and Methods: A retrospective study of ocular affections in domestic animals was conducted at referral veterinary polyclinic, Indian Veterinary Research Institute, Izatnagar from January 2002 to December 2011. The data obtained were analysed after calculating percent of distribution.

Results: Totally 799 animals were affected among which Canines and Equines were most commonly affected, followed by Cattle, Buffaloes, Caprines, Felines, Avian and lab animals. Among the disease conditions corneal opacity showed higher incidence and the Caprines and buffaloes were the most affected. Equines and canines highly affected by ocular setariasis and traumatic injury respectively. Cataract incidences were high in spitz breed and cherry eye affect mostly the Neapolitan mastiff. As per age mostly animals of more than 5 years were affected except in Caprines, ages between 1 to 5 years were most commonly affected. Left side of the eye was most commonly affected than the right side and fewer incidences were noted in both sides of the eye. Sex wise distribution showed increased incidences of eye diseases in male canines and equines and, female cattle, buffaloes and caprines.
\end{abstract}

Conclusion: Based on this study we concluded that traumatic injury and ocular setariasis are more common in Canines and Equines respectively.

Key words: breed wise data, domestic animals, eye affections, survey.

\section{I ntroduction}

Due to lack of awareness among the farmers and clinicians, the ocular problems in domestic animals are getting worsen day by day. It is not easy to diagnose them in earlier cases with the naked eyes. In order to diagnose the eye disorders, we need much more facilities. The impairment of vision caused by these diseases in working animals, pets and performing animals causes a greater economic loss to the farmers and indirectly to the society. So a detailed study is needed to diagnose and treat the eye disorders promptly $[1,2]$.

The objective of the study was to record the prevalence and document the types of eye defects in population of different domestic animals which are commonly encountered in the polyclinics. This study also brings to light the darker part of the ocular affections in domestic animals, which remains unnoticed.

\section{Materials and Methods}

A study was conducted among the domestic animals which were treated for eye disorders in the referral clinic of Indian veterinary research institute, Izatnagar during the period of 10 years from January 2002 to December 2011. These data (Table-1) were analysed based on the basis of species, age, and sex, affections of eye and disease conditions. The informa- tion was collected as per the format and the data were analyzed after calculating the percent of distribution.

\section{Results and Discussion}

There has been a dramatic increase in the ocular cases for the past ten years from January 2002 to December 2011. Totally 799 cases were affected during this period. The year wise hospital occurrence was $4.38 \%$ (2002-2003, 35 cases), 5.38\% (2003-2004, 43 cases ), 5.88\% (2004-2005, 47 cases), 6.13\% (20052006,49 cases) ,7.63\% (2006-2007, 61 cases), $10.63 \%$ (2007-2008, 85 cases), 12.14\% (2008-2009, 97 cases), $13.76 \%$ (2009-2010, 110 cases), 16.02\% (2010-2011, 128 cases), $18.02 \%$ (2011-2012, 144 cases). We could infer from the current study that there has been increase of awareness regarding ocular problems among the owners. These data were also comparable to the data of Kalaiselvan et al. [3]. In the ocular region, the eyelids, cornea or conjunctiva and lens may be affected with traumatic injuries and certain congenital or acquired tumourous growth [4].

The incidence of tumours and dermoid growth was more common in bovines $17.14 \%$ and canines $5.88 \%$ In bovines and canines tumour growths are most commonly seen in the eyelids and palpebral conjunctiva of the lower eye lid. In canines spitz and German shepherd breeds were most commonly 
Table-1. Details of ocular affections recorded

\begin{tabular}{|c|c|c|c|c|c|c|c|c|c|c|c|c|c|c|c|}
\hline \multirow[t]{2}{*}{ Species } & \multicolumn{7}{|c|}{ Disease conditions } & \multicolumn{3}{|c|}{ Age(years) } & \multicolumn{3}{|c|}{ Eye } & \multicolumn{2}{|c|}{ Sex } \\
\hline & \multicolumn{2}{|c|}{ Corneal opacity } & Amaurosis & Trauma & \multicolumn{2}{|c|}{ conjunctivitis Tumor/dermoid } & \multirow{2}{*}{$\begin{array}{c}\text { Others } \\
73\end{array}$} & \multirow{2}{*}{$\begin{array}{l}0-1 \\
34\end{array}$} & \multirow{2}{*}{$\begin{array}{c}1-5 \\
188\end{array}$} & \multirow{2}{*}{$\begin{array}{l}>5 \\
203\end{array}$} & \multirow{2}{*}{$\frac{\overline{\text { Lt }}}{172}$} & \multirow{2}{*}{$\frac{\mathbf{R t}}{160}$} & \multirow{2}{*}{$\frac{\mathbf{B t}}{93}$} & \multirow{2}{*}{$\frac{\text { Male }}{260}$} & \multirow{2}{*}{$\begin{array}{c}\text { Female } \\
165\end{array}$} \\
\hline Canine $n=$ & $=425$ & 125 & 21 & 82 & 34 & 25 & & & & & & & & & \\
\hline Equine $n=2$ & $=242$ & 68 & 7 & 17 & 9 & 1 & 2 & 12 & 104 & 126 & 74 & 122 & 46 & 174 & 68 \\
\hline Cattle $n=4$ & & 12 & 3 & 12 & 3 & 4 & 8 & 8 & 12 & 22 & 16 & 19 & 7 & 12 & 30 \\
\hline Buffalo $n=3$ & & 13 & - & 8 & 3 & 6 & 5 & 5 & 13 & 17 & 15 & 18 & 2 & 11 & 24 \\
\hline Caprine $n=$ & $=36$ & 14 & 5 & 5 & 6 & - & 6 & 4 & 20 & 12 & 15 & 18 & 3 & 17 & 19 \\
\hline Avian $n=12$ & & 3 & - & 4 & 1 & 2 & 2 & - & 12 & - & 8 & 4 & - & 5 & 7 \\
\hline Feline $n=4$ & & 1 & - & 1 & 1 & - & 1 & - & 3 & 1 & 2 & 2 & & 3 & 1 \\
\hline Total $n=79$ & & 224 & 36 & 129 & 57 & 38 & 97 & 63 & 352 & 381 & 302 & 343 & 151 & 482 & 314 \\
\hline
\end{tabular}

Equine ocular setariasis-138, cataract dog-30, cherry eye-35. (Lab animals-3) miscellaneous (corneal ulcer, Blepharitis, Desmatocele, glaucomo and epiphora etc.,)

affected then non descript animals. Reports suggest that river buffaloes are most commonly affected [5] followed by horse [6] and then camels [7]. Tumour removal by electrocautery may lead to disfigurement of the eyelid and hence this method can be avoided. Aquino et al suggested that plastic reconstruction of eyelid can be an alternative for electrocautery [8], Dermoid may occur due to the defective induction (skin instead of corneal epithelium) by corneal stromal mesenchyme [9].

Canine and equine were found to have the highest incidence of eye disorders among all the species. The 10 years data reflected the following numbers viz. Canines-425, Equine-242, Cattle-42, Buffaloes-35, Caprines-36, Avian-12, Felines-04, lab animals (one guinea pig and two rabbits)-3 and the occurrence percentage were Canines (53.1\%), Equines (30.28\%), Cattle (5.25\%), Buffaloes (4.38\%), Caprines (4.50\%), Equine $(1.50 \%)$, Felines $(0.50 \%)$, Lab animals $(0.37 \%)$. Among the eye disease conditions, corneal opacity (28\%) showed higher percentage of affection followed by trauma (16.14\%), Miscellaneous (12.14\%), Conjunctivitis (7.13\%), Tumour/dermoids (4.75\%) and Amaurosis (4.50\%).

Corneal opacity was high in Caprine $(38.88 \%)$, Buffaloes (37.14\%), and Canines (29.41\%), followed by Cattle (28.57\%), Equines (28.09\%), Avian (25\%) and Felines (25\%). In a study conducted by Osmani $e t$ $a l$., in Bangladesh occurrence of corneal opacity was found to be 208 out of the 19025 Cattle surveyed, the prevalence being $1.09 \%$. The disease occurred more frequently in young animals $(43.88 \%)$ than in adults $(15.11 \%)$ [10]. The incidence of corneal opacity among grazing animals were $2.2 \%$ among which the cross bred cows accounted for $34 \%$, Hariyana Cattle $27.6 \%$, Buffaloes 23.5\%, Goats 8.5\%, Sheep 5.8\%[11]. The main reason behind the corneal opacity in contrast with other eye disorders was attributed to poor management of commonly occurring injuries like external trauma, foreign bodies, violence and parasites [12].

This survey also included the Equine ocular setariasis, showed the higher incidence $(57.02 \%)$. Among 138 cases of occular setariasis (Including both the sexes and all the age groups) which were undergone treatment in referral clinic, 116 cases were completely cured after removal of parasites. Remaining 20 cases failed to achieve the success, and two cases seemed to have lost its eye sight because of chronic disease. Equines were generally more prone for ocular worm infestations [13], who were also found the higher percentage of ocular affections in Canines. The infestation occurs in Equines when infected mosquito laying the larva around the eye while feeding and the larva migrated to the anterior chamber and cause damage to the eye Damage to the eye caused by serrated cuticle of worm and movement of larva [14] In another study conducted by Thangadurai et al., revealed that equine recurrent uveitis, commonly referred to as moon blindness was the major vision threatening disorder in horse population[15] Affected animals show clinical signs like epiphora, photophobia, and anterior chamber opacification. It may lead to devastating sequel like synechia, cataract, and retinal detachment [16].

Traumatic injuries were more common in Canines (19.29\%) and the incidence is very less in Equine, Cattle and other species. This may be due to accidental injuries while playing, violence and foreign bodies. In equines the occurrence of traumatic injury recorded was $7.02 \%$. Traumatic injury more commonly occur in race horses it was due to exposure to sand and other solid particles that are thrown up by hooves during high speed races on a sandy race track [17]. Equine eye is enclosed with orbit but because of large size, prominent eye ball of horse may be the risk factor for causing injury by blunt trauma and penetrating injury [18].

Breed wise data among dogs revealed that spitz had the higher incidences of cataract (60\%), Neopolitan Mastiff showed the maximum occurrence of cherry eye $(62.8 \%)$. The other commonly affected animals were mongrels, followed by German Shepherd, Lhasa apso, Labrador, Doberman, Cocker Spaniel, Boxer and Great Dane. In others species there was no significant difference in breed wise occurrences. Cataract is the most common eye affections in dogs, lead to vision deficit. Many intraoperative complications occur due to lack of instruments like operative microscope and phacoemulsifier unit etc., [19] A study shows that nictating membrane prolapse was more common in Neapolitan mastiff [20], which can be removed by using conjunctival pocket technique [21] while Herrera inferred that replacement of the gland was the first line of treatment [22].

The age wise studies of dogs revealed that the 
animals of more than 5 years $(47.68 \%)$, showed higher incidence followed by middle aged animals (1-5yrs), then young (less than 1 years $7.88 \%$ ). In other species the age of the animals affected were mostly more than 5 years of age, but in Caprine maximum numbers of cases affected were between 1 and 5 years of age. Prashad and Joshi (1980) have reported 52\% cases in young grazing animals.

Among side wise affections left eye (42.92\%), showed slightly higher incidence than right eye $(37.79 \%)$ both eyes $(18.89 \%)$ indicates that these animals suffered from systemic diseases, malnutrition, and poor management. As a result these animals become unfit for production and working purposes.

The overall Sex wise distribution indicates that male animals were highly affected $(60.32 \%)$ than female animals $(39.29 \%)$. This is similar in Canines $(61.17 \%)$ and Equines $(71.90 \%)$ when compared to female Canines (38.82\%) and Equines (28.09\%). In contrast, female Cattles (71.42\%), Buffaloes (68.57\%) and Caprines (52.77\%), showed the higher incidences than males of these species.

Season wise affection revealed that many of the cases were affected during the month of January $(12.26 \%)$ followed by October $(9.63 \%)$, November $(9.51 \%)$ and December (9.13\%). These data were more contrary to the osmani et al. (2000) who reported that most of the cases of ocular affections were noticed in dry summer months $(40.5 \%)$ followed by rainy $(33.5 \%)$ and then winter (25.9\%). Further studies are recommended under different geographical location, weather, biodiversity of the host and parasites etc.

\section{Conclusion}

This study revealed importance of the diagnosis and seriousness of the eye disorders. They are problematic in canines and equines, as it is showed by increased percentage of affections during last 10 years. In canines, spitz and mongrels were more prone to eye disorders. In equines, Setariasis is the main eye disease which causes blindness and loss of perform-ance. Canines, caprines and equines are most commonly affected by trauma, corneal opacity and ocular setariasis respectively. We recommend regular ophthalmic examination and screening as an essential part of health care in domestic as well as pet animals.

\section{Authors' contribution}

MMSZ and RP designed the study. PT compiled the data, drafted and revised the manuscript with help of other authors. KK and NSM; material collection and verification. All authors read and approved the final manuscript.

\section{Acknowledgements}

Authors are thankful to The Director, Indian Veterinary Research Institute, Izatnagar for providing necessary facilities to carry out this work.

\section{Competing interests}

Authors declares that they have no competing interest.

\section{References}

1. Reichmann, P., (2008) Occurrence of ophthalmologic diseases in horses used for urban cart hauling in Londrina, PR, Brazil. Ciencia Rural, 38: 2225-2528.

2. Slater.D., (1990) Fundamentals of Veterinary Ophthalmology. II edn, W.B. Saunders, Philadelphia.

3. Kalaiselvan, A., Pawde, A. M., Kinjavdekar. P., Amarpal, Aithal .H .P., Gupta .O. P. (2009) Occurrence of ocular affections in domestic animals, Indian J Anim Sci, 79: 1020_ 1021.

4. Bernays, M.E., Flemming, D., and Peiffer, R.L.Jr. (1999) Primary corneal papilloma and squamous cell carcinoma associated with pigmentary keratitis in four dogs. J Am Vet MedAssoc, 214:215-17.

5. Rezaei, F.S., Farshid., A.A. and Saifzadeh., S. (2007) Congenital ocular dermoid cyst in river buffalo (Bubalus bubalis). Calif. J. Vet. Med,A. 54: 51-54

6. Barkyoumb, S.D., and Leipold, H.W. (1984) Nature and cause of bilateral ocular dermoids in Hereford cattle. Vet. Pathol, 21:316-324.

7. Moore, C.P., Shaner, J.B., Halenda, R.M., Rosenfeld, C.S., Suedmeyer, W.K. (1999) Congenital ocular anomalies and ventricular septal defect in a dromedary camel (Camelus dromedarus). J. Zoo Wildlife Med, 30: 423-430.

8. Aquino, S.M. (2007) Management of eyelid in the dog and cat. In: Clinical Techniques in Small Animal Practice, pp 4654.

9. Wilcock, B.P. (2007) Jubb, Kennedy and Palmer's Pathology of Domestic Animals, 5th edn. Saunders' Elsevier, Philadelphia. pp 475-476.

10. Osmani, T., Hassain, M .A., Rahman,M. M., and Alam,M .R (2000) Corneal opacity in Cattle. Bangladesh Vet, 17:42-5.

11. Prashad, J., and Joshi, S. V. (1980) Studies of clinicopathics of grazing animals in tropics corneal opacity syndrome. Indian Vet J., 57:810-15.

12. Pratap, K., Amarpal., Aithal, H. P., Hoque,M., Kinjavdekar, P. (2003) Corneal opacity and its therapeutic management in domestic animals, J Remount Vet Cors, 127:39-40.

13. Pratap, K., Amarpal., Aithal, H. P., Hoque, M., Kinjavdekar, P., Pawde, A. M. (2005) Survey of eye disorders in domestic animals. Indian JAnim Sci, 75:33-34.

14. Jaiswal, S., Singh, S. Y., Singh, B., and Singh, H. N. (2006) Ocular setariosis in a horse. Intas Polivet, I: 67-68.

15. Thangadurai.R (2010) Prevalence of Ocular Disorders in an Indian Population of Horses. J Equine Vet Sci, 30;6:326-329.

16. Danielle,T.P., Paul, E.M., Richard, R.D., James. (2004) Wardrop and equine recurrent uveitis. Arch Ophthalmol, 122:1218-1223

17. Taghipour Bazargani,T., Moaddab, S.H., Raoofi, A., Masoudifard, M., Bahonar,A.R (2011) Study of the prevalence and type of ophthalmic diseases among different breeds of horses in Tehran riding clubs. Intl $J$ of Vet Res, 5 1: 13-16.

18. Davidson,M.G., (1991) Equine ophthalmology. In: Gelatt K.N., ed. Veterinary ophthalmology, 2nd ed. Philadelphia, P.A: Lea \& Febiger. pp. 576-610.

19. Tyagi, s.p., et al (2009) Studies on the incidence, diagnosis and management of eye affections in dogs Indian J Vet Surg, 30: 26.

20. S. Bharathi, K.B.P., Raghavender, V., Gireesh Kumar, C.h., Srilatha and T.C.S. Rao (2010) Diseases of the eyelids in dogs Indian J. Vet. Surg. 31(2): 146-148.

21. Hamor, R.E. (2003) Third eyelid. In: Textbook of Small Animal Surgery, Slatter, D. H. (Ed.), 3rd edn. Saunders, Philadelphia. pp 1361-1367.

22. Herrera, D. (2005) Surgery of the eyelids. Proceedings of the WSAVA Congress, Mexico City, Mexico. 